\title{
Are Euro-Area expectations about recession phases effective to anticipate consequences of economic crises?
}

\author{
Marco Rubilar-González ${ }^{1,2}$ • Gabriel Pino ${ }^{3}$
}

Received: 7 June 2017 / Accepted: 10 December 2017 / Published online: 22 December 2017 (C) The Author(s) 2017. This article is an open access publication

\begin{abstract}
By using the Economic Sentiment Indicator and Autoregressive Markov Switching models, this paper provides an effective tool to identify and characterize expectations of business cycle phases for Germany, Spain, the Euro Area, and the European Union. This information is useful for policy makers who can focus their efforts on strengthening economies identified as more sensitive to international disturbances. Our results also reveal a lack of synchronization of the expectations across the Euro-Area. This also takes importance for policy implications given common public policies can have undesired impacts across the different Euro-Area economies.
\end{abstract}

Keywords Business cycle phases · Expectations · Economic Sentiment Indicator

JEL Classification C22 $\cdot$ D84 $\cdot$ E32

Olga Ines González Vergara is gratefully acknowledged by Marco Rubilar-González. We would like to thank the referee for valuable comments which has greatly improved this paper.

$\bowtie \quad$ Marco Rubilar-González

mrubilar@ubiobio.cl

Gabriel Pino

gpino@utalca.cl

1 Grupo de Investigación de Agronegocios, Departamento de Gestión Empresarial, Facultad de Ciencias Empresariales, Universidad del Bío Bío, Av. Andrés Bello 720, Chillán, Chile

2 Fundación Promueve, Chillán, Chile

3 Facultad de Economía y Negocios, Universidad de Talca, Av. Lircay s/n, Talca, Chile 


\section{Introduction}

After the occurrence of the Brexit, there is increasing uncertainty about its consequences for European countries, especially when additional nations are starting to evaluate leaving the Euro Area. An economic recession represents the main fear especially when the effects of the Subprime crisis are fresh on mind of agents. A lesson thought by the Sovereign crisis is that economic crises have heterogeneous impacts across Euro-Area countries. This evidence is interesting given this contradicts the achievement of an optimum currency area. This issue can certainly affect expectations of agents for future disturbances. Empirical and theoretical evidence shows that public policies across Euro Area are homogenous (Kose et al. 2012; Calderón and Fuentes 2014); nevertheless, there are still important differences across these countries (Krolzig and Toro 2005; Staehr 2008; Krugman et al. 2012; Kolasa 2013). For this reason, recession phases can be triggered by different roots and can have different characteristics among Euro-Area countries. For instance, the Sovereign crisis had dissimilar impacts across European nations. While some countries had a high and persistent unemployment rate during several years, e.g. Spain, others had minimums effects on the market labor, e.g. Germany. In such an environment, tools which help to characterize the different features of recession phases across Euro-Area countries, which seem to have marked differences, are useful to anticipate deeps impacts of future crises.

The objective of this paper is to provide a tool, which can be useful to characterize recession phases of Euro-Area economies. For this purpose, we use information pre Sovereign-crisis in order to characterize business cycle phases. Then, we are able to discuss whether this characterization coincides with the empirical evidence about the recession phases observed for these economies. To this end, we take advantage of the literature on synchronization of Euro-Area business cycles (Mundell 1961; Alesina and Barro 2002; Fidrmuc and Korhonen 2006; Bencik 2011; Morys and Ivanov 2015). In particular, we use expectation surveys and Markov Switching models to show that data alerted from heterogeneous consequences coming from a future crisis.

Expectation surveys have two advantages for the purpose of this paper. This information is currently available for long-time periods, especially for developed countries. Furthermore, there is evidence about the important role that this kind of surveys play to anticipated changes on future economic fluctuations (Nardo 2003; Vermeulen 2014; Girardi 2014; Leduc and Liu 2012; Leduc and Sill 2013). Yet, we use the Economic Sentiment Indicator (ESI henceforth), which has close relation with key economic aggregates (Nardo 2003; Pesaran and Weale 2005; Banerjee et al. 2005; Silgoner 2007; Giannone et al. 2009; Girardi 2014). In fact, there is evidence in favor of its ability to forecast turning points over the business cycle (Tayor and McNabb 2007; Ozyildirim et al. 2010). Moreover, since the introduction of Markov switching models by Hamilton (1989), these have become popular to model series that present different regimes over time, i.e. they are non-linear. This characteristic takes relevance given univariate and multivariate linear specifications are not able to efficiently model series that present structural changes or asymmetries in their evolution over time (Granger and Teräsvirta 1993; Mittnik and Niu 1994; Sensier 1996; Milas et al. 2006 ). Here, we follow Krolzig (1997) who extends the MS models by allowing a change in mean, 
variance, and parameters over the different states of an economic series which is useful to characterize business cycle phases (Goodwin 1993; Artis et al. 2004; Krolzig and Toro 2005).

In order to synthesize our analysis, we focus on four economies ${ }^{1}$ : Germany, Spain, the Euro Area, and the European Union during the monthly period from 1985:01 to 2008:02. While Germany is one of the countries less affected by the Sovereign crisis in 2010, Spain has suffered serious and deep impacts in its economy (e.g. high and persistent unemployment rate). Therefore, if expectations contained in the ESI series are a good proxy of the economic activity, they should provide German recession phases that are short and with low probability of occurrence compared to the Spanish ones. Similarly, we study expectations of economic areas with different levels of integration, i.e. the European Union and the Euro Area. This is useful to analyze whether expectations of European countries are synchronized or not.

Our results reveal a stability of expectations about German economic activity compared to the Spain case. German recession phases present a lower persistence and probability of occurrence than Spanish recession phases. Moreover, Germany possesses recession time periods shorter than Spain. These results are consistent with the empirical evidence about recession phases during the Sovereign crisis. For instance, Spain had one of the highest unemployment rates across the Euro Area. In contrast, the German economy even decreased its unemployment rate during the crisis period. ${ }^{2}$ Similar relative stability is observed for the European Union compared to the Euro Area. Recession phases have a higher persistence and longer expected time duration in the Euro Area compared to the case in the European Union. We go further and analyze the synchronization between these economies finding a low degree. This evidence is against the achievement of an optimum currency area. Thus, important differences in the evolution of the economic activity of Spain, Germany, Euro Area and European Union are exposed in this paper. This issue should be taken into account by policy makers, otherwise, centralized policies could have undesirable impacts across Euro Area countries.

This paper is organized as follows. Section 2 describes the methodology used in this paper. Section 3 presents a descriptive statistics of the data. Section 4 discusses the main results of this paper. Finally, Sect. 5 concludes this article.

\section{Methodology}

In order to identify business cycle phases, we follow the classical definition proposed by Burns and Mitchel (1946). A business cycle phase corresponds to the evolution of the economic activity between two consecutive maximum values of an economic series that contains the main characteristics of the economy. In this way, by identifying the turning points, i.e. maximum and minimum, it is possible to identify the business cycle

\footnotetext{
1 Similar results are obtained for Belgium, France, Italy, and other Euro-Area countries. For the sake of brevity, we report only the results for the four series discussed in this article. Additional results can be obtained from the authors upon request.

2 See the unemployment rate statistics of the Outlook IMF database.
} 
phases, which are expansion and recession. We use a Markov Switching Autoregressive (MS-AR henceforth) model, which allows us to identify and characterize a non-linear behavior. ${ }^{3}$ A MS-AR model assumes that switching regimes that occur at time $t$ are not observable, whose process is denoted by $S_{t}$. Hamilton $(1989,1990)$ considers that the economy can be described by two states (expansion and recession), which can be modeled as a switching regime of a stochastic process of the output growth. In particular, given a stationary series $y_{t}$ defined by an autoregressive process of order $p$, the MS-AR model with two regimes, i.e. expansion and recession, is defined by

$$
\begin{aligned}
y_{t}-\mu_{s_{t}}= & \phi_{1}\left(y_{t-1}-\mu_{s_{t-1}}\right)+\phi_{2}\left(y_{t-2}-\mu_{s_{t-2}}\right) \\
& +\phi_{3}\left(y_{t-3}-\mu_{s_{t-3}}\right)+\cdots+\phi_{p}\left(y_{t-p}-\mu_{s_{t-p}}\right)+\varepsilon_{t}
\end{aligned}
$$

where $\varepsilon_{t}$ is a white noise process such as $\varepsilon_{t} \sim$ iid $N\left(0, \sum\right)$, with constant variance $\sum$. The conditional mean $\mu_{s_{t}}$ switches from recession to expansion as follows

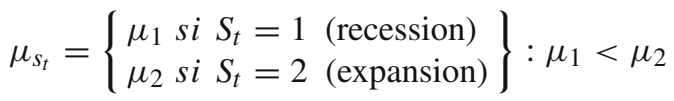

The effect of $S_{t}$ in $y_{t}$ is introduced by the conditional probability density function $p\left(y_{t} \mid S_{t}\right)$. The probability that $S_{t}$ is in state $j$ depends in its past values, i.e.

$$
p\left(S_{t}=j \mid S_{t-1}=i\right)=p_{i j}
$$

The Eq. (3) corresponds to a Markov chain with two states that has a transition probability $p_{i j}$ for all $i, j=1,2 . p_{i j}$ is the probability that the series $y_{t}$ switches from regime $i$ at period $t-1$ to the regime $j$ at period $t$. Alternatively, $p_{i i}$ is the probability that the series $y_{t}$ remains in the regime $i$ at period $t$. This probability is a measure of persistence of the business cycle phase. Additionally, useful information is provided by the unconditional probability of occurrence, i.e. expansion and recession, and the expected time duration of the two regimes. The expected time duration of regime $j$ is given by $\left(1-p_{i j}\right)^{-1}$ and the unconditional probabilities of occurrence correspond to (see Hamilton 1994 for more details):

$$
P\left(S_{t}=1\right)=\left(\frac{1-p_{22}}{2-p_{11}-p_{22}}\right), P\left(S_{t}=2\right)=\left(\frac{1-p_{11}}{2-p_{11}-p_{22}}\right)
$$

The transition probabilities for each period in our sample can be estimated by following Kim (1993) and Hamilton (1994). There are three approximations to estimate the transition probability for each sample period: filtered, smoothed, and predicted probability. The estimation of the transition probability of each sample period allows us to

\footnotetext{
3 Note that to determine which algorithm, i.e. date-then-aggregate or aggregate-then-date, is more appropriate to date turning points is an ongoing issue. For instance, see alternative evidence in Grossman et al. (2014) and Stock and Watson (2014). Additionally, Hamilton (2011) highlights the trade-off between parsimony and the efficient use of available information which implies that there is no a consensus about a specific methodology for a specific case of study.
} 
Table 1 Types of MS-AR models. Source: author's calculations based on Krolzig (1997)

\begin{tabular}{lllll}
\hline $\operatorname{MS}-\operatorname{AR}$ model & $\mu$ & $v$ & $\Sigma$ & $A_{i}$ \\
\hline $\operatorname{MSM}(R)-\operatorname{AR}(p)$ & Varying & - & Regime invariant & Regime invariant \\
$\operatorname{MSMH}(R)-\operatorname{AR}(p)$ & Varying & - & Varying & Regime invariant \\
$\operatorname{MSI}(R)-\operatorname{AR}(p)$ & - & Varying & Regime invariant & Regime invariant \\
$\operatorname{MSIH}(R)-\operatorname{AR}(p)$ & - & Varying & Varying & Regime invariant \\
$\operatorname{MSIA}(R)-\operatorname{AR}(p)$ & - & Varying & Regime invariant & Varying \\
$\operatorname{MSIAH}(R)-\operatorname{AR}(p)$ & - & Varying & Varying & Varying \\
\hline
\end{tabular}

$\overline{\mu, v, \Sigma \text {, and } A_{i} \text { represents mean, intercept, variance, and autoregressive-parameter matrix, respectively. MS }}$ stands for Markov switching. M, MH, I, IH, IA, and IAH implies a variation in mean, mean and variance, intercept, intercept and variance, intercept and autoregressive parameters, and intercept, parameters, and variance, respectively. $\mathrm{R}$ and $\mathrm{p}$ defines the number of regimes and the autoregressive order, respectively

identify expansions and recessions over the sample period (see Kim 1993; Hamilton 1994 for details about this procedure). In order to identify a change in the business cycle phase, Hamilton (1994) recommends to use the threshold value of 0.5 for the transition probability in a specific sample period.

To obtain the parameters of a MS-AR model: conditional mean $\mu_{s_{t}}$, autoregressive parameters vector $\Phi$, variance of error term $\sum$, and transition probabilities $p_{i j}$, it is necessary to maximize the conditional density function $f\left(y_{t} \mid S_{t}, \Omega_{t-1}, \theta\right)$. The evolution of the variable $y_{t}$ is driven by the regime $S_{t}$, the vector $\Omega$ that contains the available information at period $t$, and the vector of the parameters $\theta=\left(\mu_{s_{t}}, \Phi, \sum, p_{i j}\right)$. The maximization process requires a chain rule to describe the behavior of the switching regime of $y_{t}$. Hamilton (1994) assumes that the non-observable regime $S_{t}$ follows a Markov process of first order, i.e. the current regime only depends on the regime of the previous time period. ${ }^{4}$

Krolzig (1997) extends the MS-AR models to allow a change in mean, parameters, and variance over the different states of a series. Table 1 presents the different specifications proposed by Krolzig (1997), which are used in this paper to characterize business cycle phases. Given the alternative MS-AR models presented in Table 1, an exhaustive analysis is necessary to decide the most appropriate specification, which is discussed below.

Following Granger (1993) and Rubilar-González (2009), we identify the best MSAR model by using a procedure that goes from the specific to the general as follows

1. Determination of the best linear autoregressive (AR henceforth) model. Here, we follow the traditional methodology proposed by Box and Jenkins (see Box et al. 1994) to estimate the appropriate AR model. Moreover, we follow the recommendation of Van Dijk and Franses (1999) and Franses and Van Dijk (2003) by choosing the order $p$ that minimizes the Akaike criterion.

2. Test no-linearity in the selected AR model. We follow the test proposed by Hansen $(1992,1996 a, b)$ in order to test the alternative MS-AR specifications presented in Table 1.

\footnotetext{
4 A deeper discussion of the methodology presented here can be found in Rubilar-González (2009).
} 
3. Estimation of the MS-AR models for which the null hypothesis of linearity is rejected. We follow the methodology developed by Krolzig (1997).

4. Validation and selection of the final MS-AR model. First, we validate the characteristics of the non-linear models for which the null hypothesis of linearity is rejected. Specifically, we test whether changes in variance, parameters and mean are significant in the respective models. Following Krolzig (1997), we use the likelihood-ratio (LR henceforth) test to analyze the significance of these characteristics. Finally, if we have more than one MS-AR model that is validated by the LR test, we use the Hannan-Quinn criterion to discriminate between them as is recommended by Tong (1990), Clements and Krolzig (1998) and Franses and Van Dijk (2003).

We also investigate the degree of synchronization between the business cycle phases identified by the MS-AR model by estimating the corrected contingency coefficient by following Artis et al. (1997, 2004), and Fritsche and Kuzin (2005). This coefficient corresponds to the percentage of synchronization between two business cycles. This coefficient takes the value 100 for full synchronization and 0 for independence between two business cycle phases. For the economies 1 and 2, the corrected contingency coefficient is defined as follows

$$
C C_{c c}=\sqrt{\frac{A}{N+A}}\left(\frac{100}{\sqrt{0.5}}\right)
$$

where $A=\sum_{i=0}^{1} \sum_{j=0}^{1} \frac{\left[n_{i j}-n_{i, n} \cdot{ }^{\prime} / N\right]^{2}}{n_{i . n_{. j} / N}}, i$ and $j$ takes the value 1 if there is a recession phase and 0 otherwise, for the economies 1 and 2 , respectively. $n_{i j}$ is the number of periods in which the economies 1 and 2 are in the business cycle phase $i$ and $j$, respectively. $n_{i}$. and $n_{. j}$ is the total number of periods in which the economy 1 and 2 are in the business cycle phase $i$ and $j$, respectively. $N$ is the sample period.

Furthermore, we test the significance of the synchronization by following Harding and Pagan (2006) as is discussed below.

$$
\frac{S_{y t}}{\hat{\sigma}_{S x} \hat{\sigma}_{S y}}=\beta_{0}+\beta_{1} \frac{S_{x t}}{\hat{\sigma}_{S x} \hat{\sigma}_{S y}}+\varepsilon_{t}
$$

where $S_{y t}$ and $S_{x t}$ takes the value 1 for the recession phase and 0 otherwise, for the economies $y$ and $x$, respectively. $\hat{\sigma}_{S y}$ and $\hat{\sigma}_{S x}$ are the standard deviations of $S_{y t}$ and $S_{x t}$, respectively. $\beta_{0}$ is a constant and $\varepsilon_{t}$ is an error term. Hence, the null hypothesis of no concordance between two business cycles can be tested by the significance of the coefficient $\beta_{1}{ }^{5}$

\section{Data and descriptive statistics}

The ESI is based on monthly surveys to consumers and entrepreneurs about their future perceptions for variables that are of interest for them. They express their opinion about

5 The results of this test are robust to heteroscedasticity and autocorrelation. 
whether these variables will increase, decrease or remain in the same value for the next month. Therefore, the ESI corresponds to expectations of agents about different economic variables. The ESI is composed by fifteen categories that can be grouped into five economic sectors. These are industry, services, consumption, construction, and sales with the weights 40, 30, 20, 5, and 5\%, respectively. Percentage responses, i.e. increase, decrease or remain in the same value, are expresses as a balance, i.e. percentage of favorable responses minus unfavorable responses. Then, the construction of the ESI is mainly composed by three steps: (i) standardization of each observation for all categories, (ii) computation of weighted average across the fifteen categories, and (iii) standardization of weighted average which is rescaled multiplying by 10 and adding 100 so that the ESI can have an expected value of 100 and a standard deviation of 10. This indicator considers different sectors of the economy, which makes it more representative of the economic activity compared to other monthly indicators that only take into account one economic sector, e.g. the industrial production index.

This paper uses the ESI series for Germany, Spain, the Euro Area ${ }^{6}$ and the European Union $^{7}$ in the monthly period from 1985:01 to 2008:02 with the exception of Spain that is only available from 1987:02. The ESI series are freely available in the database of the European Commission, Eurostat: http://ec.europa.eu/eurostat/en/web/main/data/ database?node_code=teibs010. The selection of the sample period corresponds to the availability of data. Furthermore, in order to minimize the effects of the Sovereign crisis in 2010, we use information obtained before the Subprime crisis. This allows us to avoid effects of this crisis in order to characterize the business cycle phases for a time period previous to the economic crisis.

Figure 1 shows the ESI series for the four economies in study here. The four series do not present a clear trend over the sample period. They present an increasing pattern until 1990 where they start to decrease until 1993. After that, the ESI series present different oscillations until the last period in our sample. Spain is an exception, which seems to have a predominant decreasing trend since 2001. This reveals a predominance of pessimistic expectations during this period. The ESI series in Fig. 1 do not seem to be linear and, in particular, seem to have a cyclical behavior as is expected. Furthermore, they do not seem to be stationary given the different changes over time. ${ }^{8}$ In order to observe the relation between the ESI series and the economic activity, we graph the annual GDP growth ${ }^{9}$ and the ESI series ${ }^{10}$ in Fig. 2. Both series seem to follow a similar behavior over time. Particularly, the expectations contained in the ESI series

\footnotetext{
6 This corresponds to Belgium, Germany, Ireland, Greece, Spain, France, Italy, Luxembourg, Netherlands, Austria, Portugal, Slovenia, and Finland.

7 This corresponds to Belgium, Bulgaria, Czech Republic, Denmark, Germany, Estonia, Ireland, Greece, Spain, France, Italy, Cyprus, Latvia, Lithuania, Luxembourg, Hungary, Malta, Netherlands, Austria, Poland, Portugal, Romania, Slovenia, Slovakia, Finland, Sweden, and the United Kingdom.

8 An important characteristic of ESI series is that they do not possess trend as is shown in Fig. 1. It is for this reason that alternative methodologies to study business cycles that imply decomposition into trend and cyclical components are not applicable to ESI series, e.g. Massmann et al. (2003) and Massmann and Mitchell (2005).

9 GDP series are in quarterly frequency. The sample period corresponds to the availability of information of the Eurostat.

10 The average for each quarter is used for the ESI series.
} 

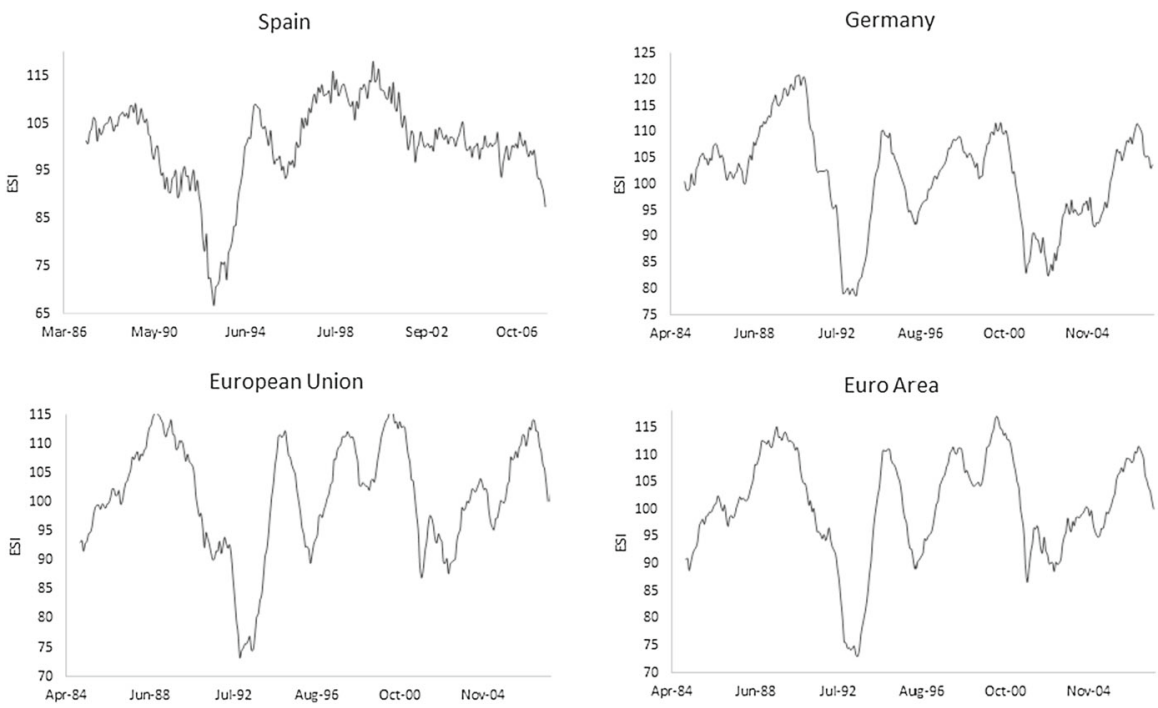

Fig. 1 ESI series. Source: author's calculations
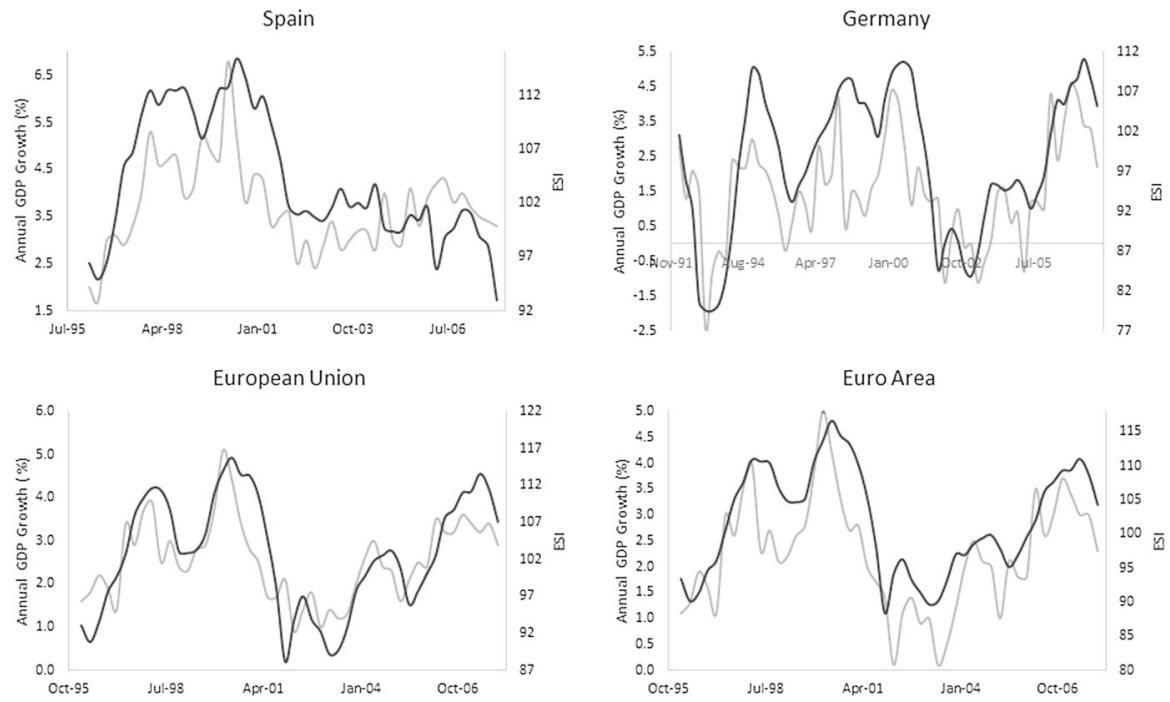

Fig. 2 ESI versus annual GDP growth. Black and gray lines correspond to ESI and GDP, respectively. Source: author's calculations

provide a smoother evolution than the economic growth. Moreover, these expectations seem to be optimistic in general given that decreases in the ESI series occur after the decreases in the GDP growth. As previously stated, Spain is an exception since 2001 where the reverse situation occurs for these series. A common issue is that all series diminish in the last periods of our sample. As a result, the ESI series seem to show a well description of the economic activity with discrepancies that are interesting to model in order to analyze how expectations evolution over time. 
Table 2 Descriptive statistics. Source: author's calculations

\begin{tabular}{llllll}
\hline Economy & Mean & $\begin{array}{l}\text { Standard } \\
\text { deviation }\end{array}$ & Persistence & \multicolumn{2}{l}{ Stationarity } \\
\cline { 5 - 6 } & & & & Levels & First difference \\
\hline Germany & 101.39 & 9.51 & $0.33^{* * *}$ & -0.12 & $-7.81^{* * *}$ \\
Spain & 100.62 & 9.54 & $-0.22^{* * *}$ & -0.71 & $-4.91^{* * *}$ \\
Euro Area & 100.63 & 9.50 & $0.50^{* * *}$ & -0.26 & $-5.23^{* * *}$ \\
European Union & 101.10 & 9.61 & $0.43^{* * *}$ & -0.34 & $-5.29^{* * *}$ \\
\hline
\end{tabular}

Persistence corresponds to the autoregressive parameter of order one. Stationarity corresponds to the Augmented Dickey-Fuller statistic where the Akaike criterion was used to determine the lag order $* * *, * *, *$ Denotes significance at the 1,5 , and $10 \%$, respectively

Table 2 presents a descriptive statistics of the ESI series; specifically, mean, variance, autoregressive coefficient of order one, and stationarity tests. The four ESI series present similar mean and variance which evidences a similarity between the four economies. In fact, we expect common features for these economies given the high integration and similar level of development across European countries. Nevertheless, the autoregressive coefficients reveal differences in the persistence across the different ESI series. For instance, while the highest value is 0.5 in the Euro Area, Spain presents a persistence of -0.22 . Despite ESI series show a non-linear behavior, we present a unit-root test as descriptive information. ${ }^{11}$ The Dickey-Fuller statistics reveal that none of the ESI series are stationary; however, all of these are stationary in first differences at $1 \%$ level of significance. ${ }^{12}$

The descriptive statistics of the ESI series reveal that their behavior seem to be closely related to the evolution of the economic activity. Furthermore, despite similarities between the ESI series, i.e. mean and variance, there are also important differences, i.e. level of persistence and evolution since 2001. For this reason, the characterization of the business cycle phases can provide important information about the evolution of expectations for the four economies in study here.

\section{Results}

Table 3 presents the selected AR models according to the procedure discussed in Sect. 2. All specifications have an insignificant constant. This could be due to a specific characteristic of the ESI series or because of a change in mean that a linear model is not able to capture. ${ }^{13}$ By using these linear AR specifications, we test the null

\footnotetext{
11 This test is not valid for non-linear series. We are aware about this issue so it is just shown to provide descriptive information about the ESI series in levels. In fact, they seem to contradict the autoregressive coefficient, which are not near to unity.

12 Similar results are obtained from the stationarity test proposed by Phillips and Perron (1988). These results can be obtained from the authors upon request.

13 Given the maximum lag length is unknown, we choose a parsimonious specification by following Clements and Krolzig (1998). Specifically, we use a maximum lag length of five and estimate all parameters for a given order.
} 
Table 3 Selected linear AR models. Source: author's calculations

\begin{tabular}{lllllll}
\hline Economy & $\mathrm{p}$ & \multicolumn{5}{l}{ Parameter order } \\
\cline { 3 - 6 } & & 1 & 2 & 3 & 4 & 5 \\
\hline Germany & 5 & $0.25^{* * *}$ & $0.16^{* *}$ & 0.02 & 0.08 & 0.06 \\
Euro Area & 3 & $0.39^{* * *}$ & $0.12^{*}$ & $0.16^{* * *}$ & - & - \\
Spain & 5 & $-0.25^{* * *}$ & 0.02 & $0.13^{* *}$ & $0.14 * *$ & $0.20^{* * *}$ \\
European Union & 3 & $0.31^{* * *}$ & $0.17 * * *$ & $0.16^{* * *}$ & - & - \\
\hline
\end{tabular}

$\mathrm{p}$ denotes the autoregressive order

$* * *, * *, *$ Denotes significance at the 1,5 , and $10 \%$, respectively

Table 4 Non-linear test. Source: author's calculations

\begin{tabular}{llllllll}
\hline Economy & MSM & MSMH & MSI & MSIH & MSIA & MSIAH & p \\
\hline Germany & $11.42 * * *$ & $9.29 * * *$ & $5.80 * *$ & $8.08^{* *}$ & $21.06^{* * *}$ & $22.16 * * *$ & 5 \\
Euro Area & $7.49 * * *$ & $15.44 * * *$ & 0.88 & $14.99 * *$ & $21.42^{* * *}$ & $24.62 * *$ & 3 \\
Spain & $3.43 *$ & $4.98^{* *}$ & $2.35^{*}$ & 1.20 & $12.13 *$ & $16.59 *$ & 5 \\
European Union & $6.71 * * *$ & $6.89 * *$ & $3.21 *$ & 4.06 & $18.43 * * *$ & $23.89 * * *$ & 3
\end{tabular}

$\mathrm{p}$ denotes the autoregressive order. MSM, MSMH, MSI, MSIH, MSIA, and MSIAH implies a Markov switching model with variation in mean, mean and variance, intercept, intercept and variance, intercept and autoregressive parameters, and intercept, parameters, and variance, respectively

$* * *, * *, *$ Denotes significance at the 1,5 , and $10 \%$, respectively

hypothesis of linearity under the alternative that there is a change in mean, variance, or coefficients. Table 4 shows the results of this test for all MS-AR cases presented in Table 1. In this way, we are able to evaluate whether there is a regime change and whether this is affecting the mean, variance, or the coefficients. Table 4 reveals that the null hypothesis of linearity is rejected in all cases at the conventional levels of significance. ${ }^{14}$ Therefore, this finding supports the use of a non-linear specification to model the ESI series for the economies in analysis here. Given that the null hypothesis of linearity is rejected for alternative specifications of MS-AR models, we follow Franses and Van Dijk (2003) and Franses et al. (2014) to identify the best specification as is discussed in Sect. 2. ${ }^{15}$ For the sake of brevity, Table 4 only presents the selected MS-AR models which are discussed below. ${ }^{16}$

Germany and the European Union present a change in mean, the Euro Area and Spain present change in mean and variance over their business cycle phases. Note that the means in the Euro Area and Spain are not significant at the conventional levels. Therefore, business cycle regimes of these countries are mainly dominated by a change in variance. ${ }^{17}$ The change in mean for Germany implies a significant decrease in the

14 There is only one exceptional case for the Euro Area, the European Union, and Spain where the null hypothesis is not rejected.

15 Note that none of the selected models present change in parameters; therefore, we do not need to test this issue.

16 All alternative specifications that are not shown here can be obtained from the authors upon request.

17 We follow Krolzig (1997) and do not consider a MS-AR model that only presents a change in variance. 
perceptions about the economic activity when there is a recession phase. The significant change in the Spanish variance suggests that expectations about its economic activity are more volatile compared to the German case. Similar situation occurs when the Euro Area and European Union are compared. In this case, the European Union does not present a chance in variance over its two regimes but possesses a significant mean during its expansion phase. Therefore, the European Union reveals a significant decrease in expectations about its economic activity when there is a recession phase. However, the Euro-Area perceptions about the economic activity seem to be more volatile.

As was discussed in the methodology section, the MS-AR models presented in Table 5 allow us to characterize the business cycles phases. Specifically, we can obtain the transition probabilities, expected time duration of the business cycle phases, and the unconditional probability of occurrence of the expansion and recession phases. Furthermore, we are able to estimate the probabilities of the expansion and recession phases for each sample period through the filtered, smoothed, and predicted probabilities. This allows us to identify the specific time periods of expansions and recessions that arise from the expectations about the economic activity. Table 6 presents these characteristics for the business cycle phases of Germany, Spain, the Euro Area, and the European Union. The transition probability associated with the persistence of the business cycle phase, i.e. $p_{i i}$, unconditional probability of occurrence, and expected time duration of the business cycle phases are presented in this Table 6. Our results reveal strength in the expectations about the German economy compared to the Spanish economy. The predominance of the expansion phase seems to be more important for Germany than Spain, which is evidenced in three features. First, while the unconditional probabilities of occurrence of the expansion phases are similar, the probability of the recession phase is lower in Germany, i.e. 0.08 compared to 0.11 in Spain. Second, the persistence of the business cycle phases reveals that the German economy is dominated by the expansion phase relative to the Spanish case. Specifically, both economies have a similar persistence in the expansion phase; however, Germany has a lower persistence of its recession phase, i.e. 0.64 compared to 0.77 in Spain. Finally, the expected time period of the expansion phase is around 11 times the recession phase in Germany, which contrasts with the Spanish case that it is around 8 times.

An interesting result arises by comparing the Euro Area and the European Union business cycle phases. Both economies present similar unconditional probabilities of occurrence of their business cycle phases; however, there is an important difference in their probabilities of persistence. The Euro Area has higher probabilities with a notable difference in the recession phase, i.e. 0.93 in the Euro Area and 0.67 in the European Union. This finding suggests that both Euro-Area business cycle phases are expected to be more stable and long lasting. In particular, the high probability of persistence for the recession phase implies that agents perceive this regime as a deep phase and for a longer time period compared to the recession phase in the European Union. This is confirmed by the expected time period of the business cycles phases where the expansion phase is 11 times the recession phase in the Euro Area and 13 times in the European Union. As a result, expectations about the economic activity in the Euro Area seem to be more stable that the ones in the European Union; however, it also implies worse expectations for the recession phase. 


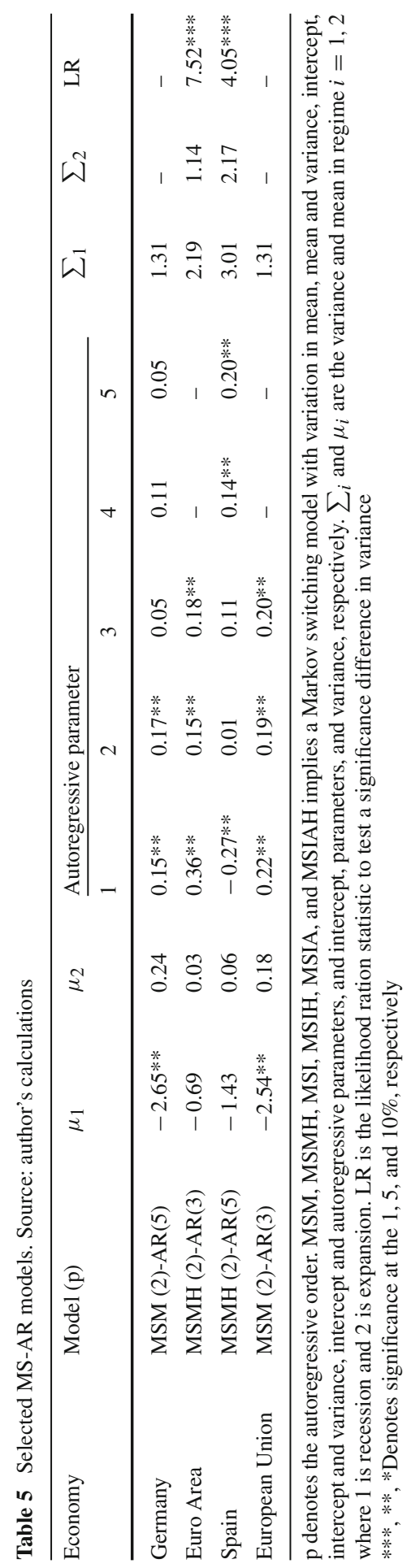


Table 6 Characteristics of business cycle phases. Source: author's calculations

\begin{tabular}{lllc}
\hline Regimen & Transition probability & $\begin{array}{l}\text { Unconditional probability } \\
\text { of occurrence }\end{array}$ & $\begin{array}{l}\text { Expected time duration } \\
\text { (months) }\end{array}$ \\
\hline Germany & & & \\
Recession & 0.64 & 0.08 & 2.79 \\
Expansion & 0.97 & 0.91 & 30.00 \\
Spain & & & 4.44 \\
Recession & 0.77 & 0.11 & 35.73 \\
Expansion & 0.97 & 0.89 & 14.86 \\
Euro Area & & & 167.28 \\
Recession & 0.93 & 0.08 & 3.06 \\
Expansion & 0.99 & 0.91 & 40.26 \\
European Union & & & \\
Recession & 0.67 & 0.07 & \\
Expansion & 0.97 & 0.93 & \\
\hline
\end{tabular}

We perform three robustness checks in order to evaluate whether the characterization of business cycle phases previously discussed is a robust outcome. First, we incorporate the monthly rate of return of the main stock market indices of the economies in study here in order to capture information regarding to the economic activity. This allows us to incorporate characteristics of financial markets across Germany, Spain, the Euro Area, and the European Union. Specifically, we use the rate of return of the DAX, IBEX35, and EUROSTOXX50 ${ }^{18}$ as covariants in our MS-AR model for Germany, Spain, and the Euro Area and the European Union, respectively. Second, we incorporate a measure of uncertainty in our estimates given uncertainty shocks can play a role affecting business cycle phases. To do so, we include the Country-level index of Financial Stress (CLIFS) as a covariant in the MS-AR model. This index measures the uncertainty in market prices by identifying simultaneous financial market turmoil across different assets (see Duprey et al. 2017 for more details). ${ }^{19}$ Finally, the ESI responses are not revised ex-post as most macroeconomic aggregates. This is a desired characteristic for the purpose of this paper given we focus on expectations of economic activity generated in a specific moment in time. Nevertheless, a noise can be incorporate into the error term due to expectations errors. We model the volatility in the error term in our MS-AR model as a Garch $(1,1)$. This allows us to capture heterogeneity which is not measured by the MS-AR model through the estimation of a MS-AR-Garch specification. ${ }^{20}$ Table 7 presents persistence probabil-

\footnotetext{
18 Stoxx Europe 600 provides similar results.

19 This index is available for Germany and Spain. We use a weighted average among the country index for the Euro Area (12 countries belonging to the Euro Area 12) and the European Union (26 out of 28 countries based on availability on information). Weights are based on the country GDP.

20 We also estimate a MS-AR model with time-varying transition probabilities. One can argue that business cycle phases can change over time in relation to macroeconomic fundaments. We follow Diebold et al. (1994) and Filardo (1994) and use a logistic functional form for the transition probabilities and the composite leading
} 
ity, unconditional probability of occurrence, and expected time duration of business cycle phases for these robustness checks. These robustness checks support the main results of this paper. In general, Spain (the Euro Area) has recession phases with higher persistence, higher probability of occurrence, and longer expected time duration than German (the European Union). This supports the use of the ESI and MS-AR models as tool to characterize business cycle phases across Euro-Area countries. Additionally, these findings show heterogeneity across business cycle phases in these economies. The stock market return has a significant (and positive) effect on expectations about German business cycle phases but this effect is insignificant for the case of Spain, the Euro Area, and the European Union. The uncertainty index has a significant (and negative) impact on expectations about business cycle phases in Germany, the Euro Area, and the European Union but an insignificant impact on Spain. Finally, the Garch specification has a significant effect on the expansion phase of Spain, and both business cycle phases on the European Union. By contrast, there is no a significant effect on German and Euro-Area business cycle phases. ${ }^{21}$

In order to identify the specific time periods of expansions and recessions, it is necessary to observe the evolution of the transition probabilities over time. Therefore, Figure 3 presents a panel of graphs for the smoothed, predicted, and filtered recession probabilities for the economies in analysis here. The threshold to determine a change in regime is 0.5 (Hamilton 1994). There are two periods in which these three probabilities cross the threshold for Germany and then identify a recession phase. These are short time periods: from 1991:02 to 1991:04 and from 1991:06 to 1991:07. Spain, on the other hand, also present two periods where probabilities cross the threshold. Nevertheless, one of them is a long period, which stays for nine months, i.e. from 1992:05 to 1993:01. Thus, Spanish recessions seem to be deeper and stay for a longer time period compared to the German case. This finding is consistent with the characterization of the business cycles phases in Table 5. By comparing the Euro Area and the European Union, we identify only one recession period for the Euro Area; however, this seems to be deep and persistent over time going from 2001:07 to 2003:01. ${ }^{22}$ This long recession phase may reflect the effect of the Asian crisis in 1997 or the uncertainty introduced by the beginning of incorporation of new members to the Euro Area, e.g. Greece in 2001. On the contrary, the European Union presents two short

indicator as a business-cycle predictor. We take these results with caution given these models are highly sensitive to functional form and starting points used in the optimization method. Overfitted and misspecified model can lead to unrealistic conclusions while a time-invariant specification can be more appropriate to characterize key information of data (Hamilton 2016). Results support findings for the Euro Area and the European Union. These estimates can be obtained from authors upon request.

21 For the sake of brevity, these results are not shown here. However, these can be obtained from authors upon request.

22 This dating does not match with recession phases published by the Euro Area Business Cycle Dating Committee (EABSDC). This is an expected outcome given EABSDC uses different type of data and also a different methodological approach. While EABSDC defines a recession phase by identifying two or more consecutive quarters with negative growth rates, we use a MS-AR model to identify business cycle phases. Furthermore, the EABSDC uses different macroeconomic aggregates to identify recession phases; however, we use expectation data about the economic activity. This is a key difference given expectations can differ from the macroeconomic data by anticipating events or intensified disturbances occurred in an economy. In our case, our findings suggest that agents perceived the events occurred in 2001 as a recession phase. 
Table 7 Robustness checks. Source: author's calculations

\begin{tabular}{llll}
\hline Regimen & $\begin{array}{l}\text { Transition } \\
\text { probability }\end{array}$ & $\begin{array}{l}\text { Unconditional proba- } \\
\text { bility of occurrence }\end{array}$ & $\begin{array}{l}\text { Expected time duration } \\
\text { (months) }\end{array}$ \\
\hline
\end{tabular}

Including financial market index return (FMIR) as a covariant

Germany

$\begin{array}{rrrr}\text { Recession } & 0.53 & 0.07 & 2.11 \\ \text { Expansion } & 0.96 & 0.93 & 28.01 \\ \text { Spain } & & & 3.11 \\ \text { Recession } & 0.68 & 0.52 & 2.86 \\ \text { Expansion } & 0.65 & 0.48 & \end{array}$

Euro Area

$\begin{array}{lllr}\text { Recession } & 0.91 & 0.07 & 11.41 \\ \text { Expansion } & 0.99 & 0.93 & 143.65\end{array}$

European Union

$\begin{array}{lllr}\text { Recession } & 0.64 & 0.07 & 2.80 \\ \text { Expansion } & 0.97 & 0.93 & 38.83\end{array}$

Including country-level index of financial stress (CLIFS) as a covariant Germany

$\begin{array}{llrr}\text { Recession } & 0.70 & 0.10 & 3.32 \\ \text { Expansion } & 0.97 & 0.90 & 30.07\end{array}$

Spain

$\begin{array}{lllr}\text { Recession } & 0.77 & 0.19 & 4.28 \\ \text { Expansion } & 0.94 & 0.81 & 17.99\end{array}$

Euro Area

$\begin{array}{lllr}\text { Recession } & 0.89 & 0.11 & 8.99 \\ \text { Expansion } & 0.99 & 0.90 & 76.86\end{array}$

European Union

$\begin{array}{lllr}\text { Recession } & 0.87 & 0.31 & 7.61 \\ \text { Expansion } & 0.94 & 0.69 & 17.01\end{array}$

Including a specification GARCH $(1,1)$

Germany

$\begin{array}{llrr}\text { Recession } & 0.50 & 0.05 & 2.14 \\ \text { Expansion } & 0.97 & 0.95 & 36.86\end{array}$

Spain

$\begin{array}{lllr}\text { Recession } & 0.81 & 0.03 & 8.00 \\ \text { Expansion } & 0.99 & 0.97 & 119.00\end{array}$

Euro Area

$\begin{array}{lllr}\text { Recession } & 0.94 & 0.07 & 20.00 \\ \text { Expansion } & 0.99 & 0.93 & 127.50\end{array}$

European Union

$\begin{array}{llrr}\text { Recession } & 0.54 & 0.06 & 2.00 \\ \text { Expansion } & 0.95 & 0.94 & 28.78\end{array}$


Table 7 continued

\begin{tabular}{lllr}
\hline Regimen & $\begin{array}{l}\text { Transition } \\
\text { probability }\end{array}$ & $\begin{array}{l}\text { Unconditional proba- } \\
\text { bility of occurrence }\end{array}$ & $\begin{array}{l}\text { Expected time duration } \\
\text { (months) }\end{array}$ \\
\hline $\begin{array}{l}\text { Including FMIR, CLISFS and GARCH (1,1) } \\
\text { Germany }\end{array}$ & & \\
$\quad$ Recession & 0.36 & 0.07 & 1.80 \\
Expansion & 0.95 & 0.93 & 23.09 \\
Spain & & & \\
Recession & 0.94 & 0.09 & 15.00 \\
Expansion & 0.99 & 0.91 & 159.00 \\
Euro Area & & & 19.00 \\
Recession & 0.92 & 0.08 & 116.00 \\
Expansion & 0.99 & 0.92 & 1.56 \\
European Union & & & 23.70 \\
Recession & 0.44 & 0.06 & \\
Expansion & 0.92 & 0.94 & \\
\hline
\end{tabular}

recession periods, i.e. from 1992:07 to 1992:11 and from 2001:08 to 2001:11. ${ }^{23}$ This finding supports longer and deeper recession periods for the Euro Area compared to the European Union. A last issue is that the four economies in study here are in the expansion phase during the last period of our sample. This implies that the Sovereign crisis and the U.S. subprime crisis do not have an important impact in the estimations presented in this paper.

In relation to the synchronization of expectations, our results reveal the following percentages: 33\% for Spain and German, 7\% for Spain and the Euro Area, $61 \%$ for Spain and the European Union, $41 \%$ for Germany and the Euro Area, $72 \%$ for Germany and the European Union, and 18\% for the Euro Area and the European Union. Artis et al. (1997) use a percentage below $40 \%$ to determine a low degree of synchronization. According to this criterion, we detect a low level of synchronization for Spain and Germany, Spain and the Euro Area, and the Euro Area and the European Union. In addition, the synchronization between Germany and the Euro Area also seems to be low given it is barely above $40 \%$. These findings are interesting given Germany and Spain seem to be more synchronized with the European Union than with the Euro Area. In order to support the lack of synchronization for these economies, we test the significance of the synchronization as is shown in Eq. (6). Our findings indicate that the null hypothesis is not rejected at the conventional levels of significance for all countries with low synchronization. Furthermore, the null of no concordance is

\footnotetext{
23 When the three probability measures cross the threshold value, we identify a recession phase and we measure it as the largest time period identified across these three measures.
} 

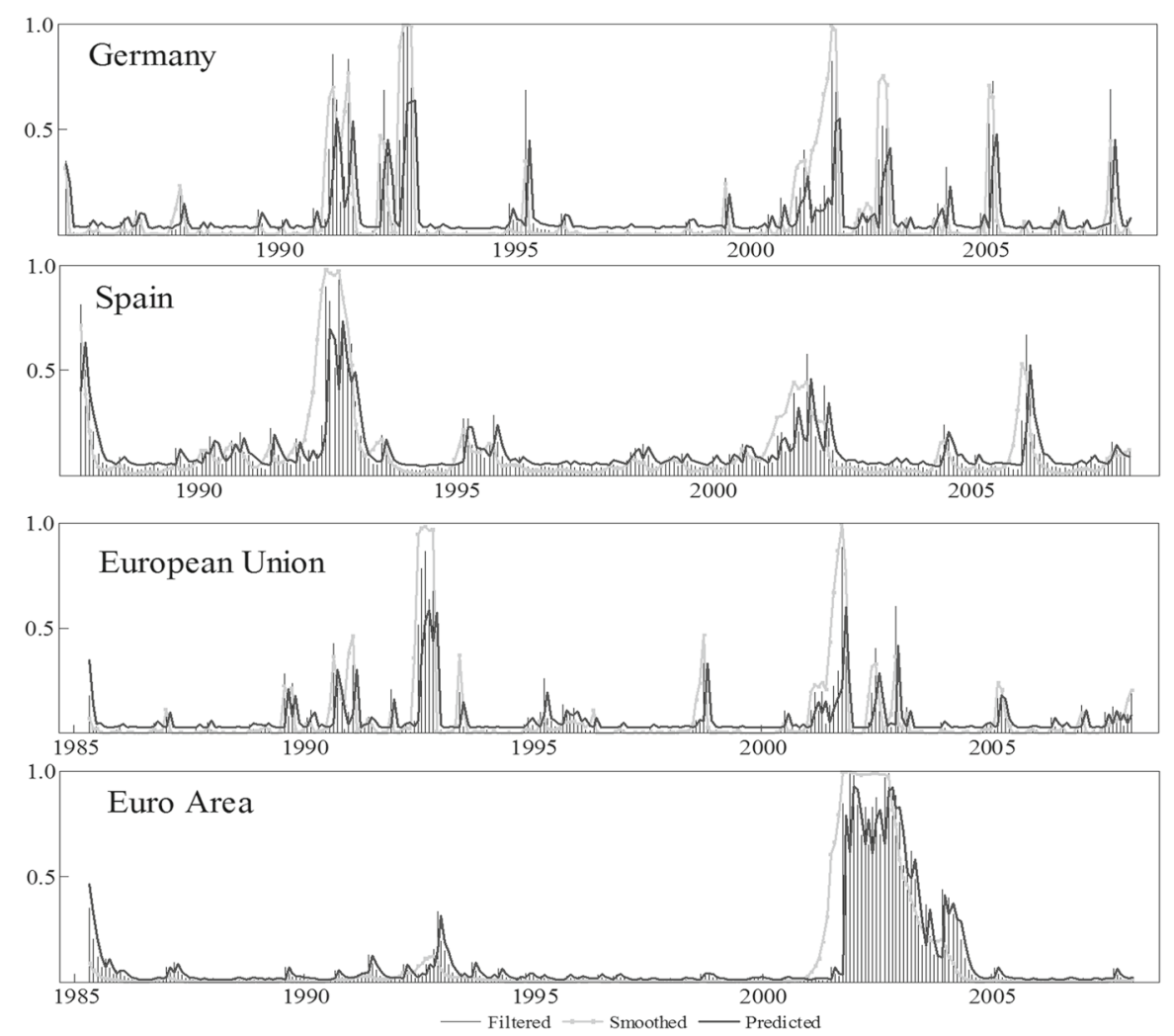

Fig. 3 Transition probability of the recession phase. Source: author's calculations

not rejected for the synchronization between Germany and the Euro Area. ${ }^{24}$ As a result, this analysis supports that the expectations across Euro-Area countries present important discrepancies. Therefore, our findings reveal a lack of synchronization for the Euro-Area economies in study here. This low level of concordance suggests a lack of common movements, which implies that there is no a latent variable that can drive a common business cycles of the Euro-Area expectations in analysis here.

Despite the similar characteristics and high level of integration of the economies in analysis here, we detect important differences across their expectations. This implies that an economic crisis can have heterogeneous impacts across the expectations of Euro-Area agents. In particular, a recession in the Spanish economy is expected to have a higher probability of occurrence, higher degree of persistence, and stay for a longer time period compared to the German economy. These findings seem to be coherent with evidence about the economic crisis in 2010. A clear example is that the German economy only had a negative economic growth in 2009; however, Spain had

$24 P$ values for the null hypothesis are $0.10,0.16,0.15$, and 0.43 for the synchronization of Spain-Germany, Spain-the Euro Area, Germany-the Euro Area, and the Euro Area-the European union, respectively. More details about this test can be obtained from the authors upon request. 
a negative economic growth during 2009, 2010, 2012, and 2013. ${ }^{25}$ Furthermore, the German unemployment rate even decreased during the crisis period, i.e. $7.8 \%$ in 2009 and 5.3\% in 2013, while the Spanish unemployment rate had an increasing trend since 2009 , i.e. $17.9 \%$ in 2009 and $26.1 \%$ in $2013 .{ }^{26}$ In addition, expectations are more pessimistic for the recession phases of the Euro Area than the ones in the European Union. The empirical evidence again seems to be in line with this finding. While the European Union only had a negative economic growth in 2009, the Euro Area had a negative economic growth in 2009, 2012, and 2013. ${ }^{27}$ As a consequence, the concordance of the characterization of business cycle phases presented here suggests that expectations survey data is a useful tool for policy makers in order to study the business cycle to across the Euro Area.

Our findings are useful for policy implications. In order to enjoy the benefits of an optimum currency area, Euro-Area integrants should fulfill a series of requirements that allow them to homogenize their economies. For this reason, the synchronization of expectations plays an important role to minimize heterogeneous impacts of centralized policies, i.e. monetary policy. This paper reveals significant differences in the expectations for Germany, Spain, and the Euro Area. Therefore, level of requirement fulfillment across Euro-Area countries does not seem to be enough to synchronize expectations. This may be the reason of the heterogeneous impacts of the Sovereign crisis across Euro-Area countries. For instance, different European economies had booms in housing prices during the economic crisis in 2010; however, Germany did not have this problem (Krugman et al. 2012). Furthermore, there are important differences in the impacts on the employment that can be related to the heterogeneity in the wage flexibility (Pino and Soto 2014), which contradicts the achievement of the optimum currency area.

\section{Conclusions}

The study of Euro-Area expectations and their implications for recession phases is useful to anticipate heterogeneous (and undesired) impacts of common public policies or international shocks across European economies. Furthermore, it helps to analyze whether the Euro Area has reached an optimum currency area. This paper uses the ESI and the Markov switching methodology to analyze recession phases and synchronization of expectation of Germany, Spain, the Euro Area, and the European Union. By using the pre-crisis data from 1985:01 to 2008:02, our results reveal important differences across the expectations about economic activity of Euro-Area economies. The characterization of recession phases provided by our estimates coincides with empirical evidence during the Sovereign crisis. Therefore, our approach is useful to improve information for policy makers in charge of monitoring economic activity. This issue takes importance for the contemporaneous situation of European economies where uncertainty has increased during the last years. For instance, an update of informa-

\footnotetext{
25 See economic growth statistics of the IMF Outlook database October 2014.

26 See unemployment rate statistics of the IMF Outlook database October 2014.

27 See economic growth statistics of the Eurostat.
} 
tion about expectation can be used to identify which European countries can be more affected by a future economic crisis. Then, policy makers can focus their efforts to strength these economies. In addition, our results present evidence of important disparities in the expectations of Euro-Area agents, e.g. the high volatility of Spanish expectations compared to German expectations. This evidence is against the achievement of an optimum currency area. Therefore, policy makers should be aware that common public policies, e.g. monetary policy, can have unequal and undesired impacts across the different Euro-Area countries.

\section{Compliance with ethical standards}

Conflict of interest The authors declare that they do not have conflict of interest.

Informed consent Data used in this article, i.e. the Economic Sentiment Indicator (ESI) is freely available by the European Commission, Eurostat. Therefore, informed consent was obtained from all individual participants during the construction of the ESI data.

Open Access This article is distributed under the terms of the Creative Commons Attribution 4.0 International License (http://creativecommons.org/licenses/by/4.0/), which permits unrestricted use, distribution, and reproduction in any medium, provided you give appropriate credit to the original author(s) and the source, provide a link to the Creative Commons license, and indicate if changes were made.

\section{References}

Alesina A, Barro R (2002) Currency unions. Q J Econ 117(2):409-436

Artis M, Krolzig H-M, Toro J (2004) The European business cycle. Oxf Econ Pap 56:1-44

Artis MJ, Kontolemis ZG, Osborn DR (1997) Business cycles for G7 and European countries. J Bus 70:249-279

Banerjee A, Marcellino M, Masten I (2005) Leading indicators for Euro-Area inflation and GDP growth. Oxf Bull Econ Stat 67:785-813

Bencik M (2011) Business cycle synchronisation between the V4 countries and the Euro Area. Bank of Slovakia, Working and discussion paper no 1

Box GEP, Jenkins GM, Reinsel GC (1994) Time series analysis: forecasting and control, 3rd edn. Prentice Hall, New Jersey

Burns AF, Mitchel WC (1946) Measuring business cycles. National Bureau of Economic Research, New York

Calderón C, Fuentes JR (2014) Have business cycles changed over the last two decades? An empirical investigation. J Dev Econ 109:98-123

Clements MP, Krolzig H-M (1998) A comparison of the forecast performance of Markov-switching and threshold autoregressive models of US GNP. Econom J 1:47-75

Diebold FX, Joon-Haeng L, Weinbach GC (1994) Regime switching with time-varying transition probabilities. In: Hargreaves CP (ed) Nonstationary time series analysis and cointegration. Oxford University Press, Oxford

Duprey T, Klaus B, Peltonen T (2017) Dating systemic financial stress in the EU countries. J Financ Stab 32:30-56

Fidrmuc J, Korhonen I (2006) Meta-analysis of business cycle correlation between the Euro Area and the CEECs. J Comp Econ 34:518-537

Filardo AJ (1994) Business cycle phases and their transitional dynamics. J Bus Econ Stat 12:299-308

Franses PH, Van Dijk D (2003) Non-linear time series models in empirical finance, 1st edn. Cambridge University Press, Cambridge

Franses PH, Van Dijk D, Opschoor A (2014) Time series models for business and economic forecasting, 2nd edn. Cambridge University Press, Cambridge

Fritsche U, Kuzin V (2005) Prediction of business cycle turning points in Germany. Jahrbücher für Nationalökonomie und Statistik 225:22-43 
Giannone D, Reichlin L, Simonelli S (2009) Nowcasting Euro Area economic activity in real time: the role of confidence indicators. Natl Inst Econ Rev 210:90-97

Granger CWJ (1993) Strategies for modelling nonlinear time-series relationships. Econ Rec 69:233-238

Granger CWJ, Teräsvirta T (1993) Modelling nonlinear economic relationships. Oxford University Press, Oxford

Girardi A (2014) Expectations and macroeconomic fluctuations in the Euro Area. Econ Lett 125:315-318

Goodwin TH (1993) Business-cycle analysis with a Markov-switching model. J Bus Econ Stat 11:331-339

Grossman V, Adrienne M, Martínez-García E (2014) A contribution to the chronology of turning points in global economic activity (1980-2012) Federal Reserve Bank of Dallas Globalization and Monetary Policy Institute working paper no. 169. SSRN: https://ssrn.com/abstract=2383913 or https://doi.org/ $10.2139 /$ ssrn.2383913

Hamilton JD (1989) New approach to the economic analysis of nonstationary time series and the business cycle. Econometrica 57:357-384

Hamilton JD (1990) Analysis of time series subject to changes in regime. J Econom 45:39-70

Hamilton JD (1994) Time series analysis. Princeton University Press, Princeton

Hamilton JD (2011) Calling recessions in real time. Int J Forecast 27:1006-1026

Hamilton JD (2016) Macroeconomic regimes and regime shifts. In: Taylor JB, Woodford M (eds) Handbook of macroeconomics, Vol 2A, Chap 3, 1st edn. Elsevier, Amsterdam, pp 163-201

Hansen BE (1992) The likelihood ratio test under nonstandard conditions: testing the Markov switching model of GNP. J Appl Econom 7:61-82

Hansen BE (1996a) Erratum: The likelihood ratio test under nonstandard conditions: testing the Markov switching model of GNP. J Appl Econom 11:195-198

Hansen BE (1996b) Inference when a nuisance parameter is not identified under the null hypothesis. Econometrica 64:413-430

Harding D, Pagan A (2006) Synchronization of cycles. J Econom 132:59-79

Kim CJ (1993) Unobserved-components time series models with Markov-switching heteroskedasticity: changes in regime and the link between inflation rates and inflation uncertainty. J Bus Econ Stat 11:341-349

Kolasa M (2013) Business cycles in EU new member states: how and why are they different? J Macroecon 38:487-496

Kose MA, Otrok C, Prasad E (2012) Global business cycles: convergence or decoupling? Int Econ Rev 53:511-538

Krolzig H-M (1997) Markov switching vector autoregressions: modelling, statistical inference and application to business cycle analysis. Lecture notes in economics and mathematical systems. Springer, Berlin

Krolzig H-M, Toro J (2005) Classical and modern business cycle measurement: the European case. Span Econ Rev 7:1-21

Krugman PR, Obstfeld M, Melitz MJ (2012) International economics. Theory and policy, 9th edn. The Pearson Series in Economics, Boston

Leduc S, Liu Z (2012) Uncertainty shocks are aggregate demand shocks. Working paper series 2012-10, Federal Reserve Bank of San Francisco

Leduc S, Sill K (2013) Expectations and economic fluctuations: an analysis using survey data. Rev Econ Stat 95:1352-1367

Massmann M, Mitchell J (2005) Reconsidering the evidence: are Euro Area business cycles converging? J Bus Cycle Meas Anal 3:275-307

Massmann M, Mitchell J, Weale M (2003) Business cycles and turning points: a survey of statistical techniques. Natl Inst Econ Rev 183:90-106

Milas C, Rothman P, Van Dijk D (2006) Nonlinear time series analysis of business cycles (contributions to economic analysis). Elsevier, Oxford

Mittnik S, Niu Z (1994) Asymmetries in business cycles. Econometric techniques and empirical evidence. Kluwer, Boston

Morys M, Ivanov M (2015) The emergence of a European region: business cycles in South-East Europe from political independence to World War II. Eur Rev Econ Hist 19(4):382-411

Mundell RA (1961) A theory of optimum currency areas. Am Econ Rev 51:657-665

Nardo M (2003) The quantification of qualitative survey data: a critical assessment. J Econ Surv 17:645-668

Ozyildirim A, Schaitkin B, Zarnowitz V (2010) Business cycles in the Euro Area defined with coincident economic indicators and predicted with leading economic indicators. J Forecast 29:6-28 
Pesaran MH, Weale M (2005) Survey expectations. CESifo, Working paper no 1599

Pino G, Soto A (2014) Analysis of wage flexibility across the Euro Area: evidence from the process of convergence of the labour income share ratio. Appl Econ 46:3572-3580

Phillips P, Perron P (1988) Testing for unit root in time series regression. Biométrica 75:335-346

Rubilar-González MA (2009) Un estudio econométrico sobre la Modelización del ciclo económico en la Euro Area. Masters Thesis, Universidad de Concepción

Sensier M (1996) Investigating business cycle asymmetries in the UK. Doctoral Thesis, University of Sheffield

Silgoner M (2007) The economic sentiment indicator: leading indicator-properties in old and new EU members states. J Bus Cycle Meas Anal 2007(2):199-2015

Staehr K (2008) Fiscal policies and business cycles in an enlarged Euro Area. Econ Syst 32:46-69

Stock JH, Watson MW (2014) Estimating turning points using large data sets. J Econom 178:368-381

Tayor K, McNabb R (2007) Business cycles and the role of confidence: evidence for Europe. Oxf Bull Econ Stat 69:185-208

Tong H (1990) Non-linear time series. A dynamical system approach. Oxford University Press, Oxford

Van Dijk D, Franses PH (1999) Modelling multiple regimes in the business cycle. Macroecon Dyn 3:311340

Vermeulen P (2014) An evaluation of business survey indices for short-term forecasting: balance method versus Carlson-Parkin method. Int J Forecast 30:882-897

Publisher's Note Springer Nature remains neutral with regard to jurisdictional claims in published maps and institutional affiliations. 